\section{Mulheres, imprensa e higiene: a medicalização do parto na Bahia (1910-1927)}

Women, the press, and hygiene: the medicalization of birth in Bahia (1910-1927)
AMARAL, Marivaldo Cruz do. Mulheres, imprensa e higienização: a medicalização do parto na Bahia (1910-1927). História, Ciências, Saúde Manguinhos, Rio de Janeiro, v.15, n.4, out.-dez. 2008, p.927-944.

Resumo

Discute a inserção da imprensa leiga como veículo de disseminação da agenda higienista na cidade de Salvador, Bahia, em princípios do século XX. Os alvos dos articulistas foram o parto medicalizado e os novos padrões de atenção ao corpo feminino e aos recém-nascidos. A Maternidade Climério de Oliveira contou com o apoio irrestrito da imprensa, que não poupou esforços para apresentar esse espaço como ideal para o parto hospitalar.

Palavras-chave: Maternidade Climério de Oliveira; assistência ao parto; imprensa; Salvador (BA).

\section{Abstract}

The article discusses the role played by the lay press in disseminating the hygienist agenda in the city of Salvador, Bahia, in the early twentieth century, when journalists were writing about medicalized birth and the new standards of attention to the female body and to newborns. The Climério de Oliveira Maternity Hospital enjoyed the unrestricted support of the press, which went out of its way to portray the facility as ideal for hospital births.

KEYWORDS: Climério de Oliveira Maternity Hospital; birth and delivery care; press; Salvador, Bahia.

\author{
Marivaldo Cruz do Amaral \\ Professor da Universidade Federal do Recôncavo da Bahia \\ Rua Icapuí, 127/1102, bloco B \\ 40296-610 - Salvador - BA Brasil \\ marivaldo.doamaral@hotmail.com
}

Recebido para publicação em maio de 2007. Aprovado para publicação em junho de 2008.

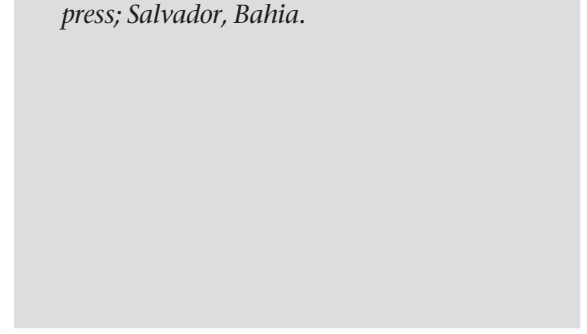


$\mathrm{N}^{\mathrm{s}}$ o início do século XX, a sociedade baiana passou por mudanças na sua estrutura urbana e social e, concomitantemente, inseriu novos temas na agenda higienista ${ }^{1}$, entre elas a fundação da maternidade da Bahia. A mulher baiana foi posta diante de novas possibilidades de atendimento médico na disseminação da prática do parto hospitalar, e uma ampla campanha educativa visava estabelecer novos valores, novos padrões de comportamento e a disciplinarização dos seus corpos.

Esse processo de modernização era fruto de um movimento iniciado na Europa no século XVIII, momento em que as cidades européias vivenciaram o crescimento populacional e o aumento das epidemias. Esse quadro gerou uma inquietude político-sanitária, promovendo uma intervenção sem limites dos médicos como normatizadores do comportamento humano (Foucault, 1985). Esse movimento ganhou força no Brasil no início do século XX. O saber médico acadêmico interferiu na vida da sociedade, estabelecendo novos preceitos no cuidado com a saúde. Essa agenda higienista somava-se a um amplo processo de modernização que mudaria a estrutura social e urbana nas capitais brasileiras.

O papel desempenhado pela imprensa baiana nesse período foi fundamental para que os ideais médicos, representantes das aspirações e perspectivas das elites, fossem sedimentados na vida cotidiana da mulher baiana. Neste artigo, elegemos as publicações feitas pelo jornal Diário de Notícias como fonte privilegiada para discutir a campanha educativa desenvolvida na Bahia do início do século XX, que objetivava apoiar a medicalização do parto através da Maternidade Climério de Oliveira, bem como estabelecer novos padrões de comportamento nos cuidados com o corpo, com as crianças e na vida social.

Historicamente, a imprensa foi utilizada como estratégia de construção de consensos e dissensos, forjadora de costumes, veículo de propaganda política e de formação de opiniões (Faria Filho, 2002). Portanto, essa fonte é valiosa para a pesquisa histórica, pois possibilita ao historiador novas interpretações e impressões sobre os episódios sociais.

A produção historiográfica brasileira costuma utilizar a imprensa como fonte complementar. Entretanto, nos últimos anos vem se consolidando como corpus documental que possibilita a compreensão das várias dimensões do processo histórico, por exemplo a ressonância que determinadas campanhas educativas têm no contexto social (Carvalho, Araújo, Gonçalves Neto, 2002; Ferreira, 2004; Freire, 2006).

Como veículo educativo, a imprensa tenta, entre outras coisas, padronizar comportamentos e legitimar instituições. A insistência em publicar certos temas, discursos e mensagens contribuiu consideravelmente para que houvesse adesão a proposições capazes de engendrar novas mentalidades (Gonçalves Neto, 2002; Bastos, 2002).

Luis Otávio Ferreira (2004, p.94-95) observa que os periódicos médicos assumiram um papel estratégico na "afirmação científica da medicina" na Europa do século XVIII. No Brasil do século XIX, os periódicos médicos mantiveram as mesmas estratégias européias, dando visibilidade às ações dos médicos e convencendo o público leigo a respeito da medicina.

$\mathrm{Na}$ Bahia, apesar de destinada a um público de estudantes de medicina e médicos, a Gazeta Medica da Bahia também contribuiu significativamente na divulgação das discussões médicas sobre variadas temáticas ligadas à saúde da população. Entretanto, foram os jornais de grande circulação os responsáveis pela propagação da agenda sanitária no cotidiano da sociedade. 
Nessa perspectiva, os jornais publicados na Salvador republicana do início do século XX constituem valiosa fonte para compreendermos a campanha educativa desenvolvida pelos médicos da Faculdade de Medicina da Bahia, na tentativa de medicalizar o corpo das mães baianas, pois a imprensa não mediu esforços para apoiar os preceitos da nova agenda higienista.

A imprensa baiana foi grande aliada do projeto medicalizador, promovendo um estímulo educativo, seja através de publicações que falavam da maternidade como exemplo de modernidade e civilidade, seja por meio das notas de agradecimento pelo bom atendimento médico recebido. Essas notas eram publicadas diariamente nos jornais e, geralmente, feitas pelos maridos que se mostravam gratos aos médicos da Maternidade Climério de Oliveira por terem cuidado bem de suas esposas, tendo-as curado ou até mesmo feito os seus partos. Esses anúncios vinham de pessoas que compunham as camadas privilegiadas da sociedade baiana e que também constituíam o público leitor dos jornais de circulação diária.

O apoio da imprensa ao projeto de medicalização do parto não se restringiu a anunciar a Maternidade como espaço médico científico em que as mulheres eram bem tratadas. As publicações de notas de agradecimento por doações feitas davam visibilidade pública a muitos mantenedores da instituição.

Os trabalhos de caridade desenvolvidos pelas mulheres de famílias abastadas eram amplamente divulgados pela imprensa local. Vale salientar que o apoio dado pelas senhoras da elite baiana não passava despercebido pelos médicos e pela Faculdade de Medicina da Bahia. Essa disposição no desenvolvimento da assistência social era bastante peculiar entre as feministas baianas ${ }^{2}$. O discurso feito por Augusto Vianna, então diretor da Faculdade de Medicina, por ocasião da inauguração da Maternidade Climério de Oliveira, destacava a ação das mulheres do Comitê de Senhoras da Bahia, exaltando com freqüência a importância do serviço prestado por elas à sociedade baiana: "O que posso e devo affirmar jubilosamente é que a esse comitê cabem os mais viridentes louros desta Victória excelsa que hoje, com satisfação indissivel, festejamos" (Diário de Notícias, 3 nov. 1910, p.3).

Em 1914, Menandro Filho, então diretor da Maternidade Climério de Oliveira, agradeceu a Balbina Pereira Vianna, pela doação que a mesma fizera à Maternidade. Nesta nota, percebese não só o valor cristão, mas também o valor político implícito nas palavras do orador:

Exma. Sra. D. Balbina Pereira Vianna - queira V. Ex. aceitar as minhas respeitosas saudações.

É com o mais intimo contentamento que cumpro o gratíssimo dever de, em nome da Maternidade, agradecer a V. ex. a valiosa dádiva que acaba de fazer. Gesto de uma suavissima fidalguia, as bênçãos do céu retribuil-o-ão com sobras, attenta a grande pureza do sentimento que o ditou.

Em nome da Maternidade, pois, ou mais particularizando, em nome dessas criaturas que aqui vem buscar cuidados que porventura em outras partes não lograssem ter, eu agradeço o auxílio que $\mathrm{V}$. ex. acaba de prestar, prova evidente de que não se apaga jamais da memória dos bons a lembrança de que a pratica constante do bem foi apanágio que Deus lhes fez.

De V. ex. cro. atto e respeitador (Diário de Notícias, 24 jul. 1914, p.2).

Publicações dessa natureza, além de promoverem a imagem de quem doava, serviam como estímulo à elite para manter a prática da caridade. Destacando o fazer caridade como uma prática herdada de Cristo, a imprensa baiana evidenciava o seu importante papel no processo de formação da opinião pública local no início do século XX. 
Os jornais noticiavam a caridade como um exemplo de 'fidalguia', uma prática cristã de uma sociedade que se preocupava com sua população pobre, um exemplo de civilidade cristã. Vale salientar as listas que, com freqüência, eram publicadas na íntegra por esses jornais. Nelas encontravam-se, na maioria das vezes, mulheres ricas da sociedade baiana.

A imprensa trabalhava intensamente o processo de formação de opinião, salientando a importância da filantropia na sociedade baiana. Suas publicações eram um meio utilizado para incentivar o público leitor a se tornar mantenedor de instituições como a Maternidade Climério de Oliveira, sob a alegação de estar contribuindo para o favorecimento da justiça social. Em artigo publicado no Diário de Notícias (14 out. 1914), Paulo Mantegazza afirmou que "assim como o sol ilumina e aquece toda a terra, do mesmo modo o nosso affecto deve estender-se à humanidade inteira, porque ella não é senão a grande família a que pertencemos".

Como mostra Sanglard (2005), a filantropia foi um dos veículos de condução do Brasil à modernização. E a imprensa foi sua principal agenciadora política. Ao veicular imagens de senhorinhas casadas com importantes personalidades políticas, com ricos proprietários, e de mulheres integrantes de famílias baianas tradicionais, médias ou ricas, o jornal estimulava a prática da caridade, mostrava festas beneficentes, anunciava nomes de participantes e por vezes concluía o texto com a frase: "Toda gente chic estava presente" (Diário de Notícias, 21 set. 1927, p.3).

A imprensa contribuiu para a consolidação da maternidade na Salvador republicana do início do século XX ao dar visibilidade à Climério de Oliveira como local moderno, civilizado, limpo e agradável para todos, independentemente da camada social. Estimulou a sociedade a fazer doações para sua manutenção e publicou notas de agradecimentos que demonstravam a satisfação daqueles que utilizavam seus serviços.

Os temas abordados diariamente pelos jornais reforçam a nossa convicção de que a imprensa foi forte aliada do projeto higienizador. Este pretendia intervir em vários segmentos da vida urbana. Ao pontificar sobre o traçado das ruas, a organização das feiras e os outros aspectos relacionados à saúde da população, a nova agenda higienista buscava adaptar padrões europeus à realidade local.

A busca do ideal de cidade referenciada nas grandes metrópoles européias mudaria também a trajetória dos atores sociais que protagonizavam o cotidiano das cidades brasileiras do início do século XX. A civilidade que as elites almejavam passava a reconfigurar costumes e valores. O esforço para disciplinar os corpos sinalizava espaços a alterar ou a criar para as pessoas que circulavam pela cidade. As reclamações publicadas diariamente nos jornais não deixam dúvida de que o trânsito de mulheres e crianças pobres pelas ruas causava incômodo às elites. As mulheres pobres buscavam sua sobrevivência e a de sua prole nas ruas, desempenhando atividades de ganho. Eram inúmeras as reclamações publicadas nos jornais sobre o comportamento 'imoral' dessas mulheres, os namoros e até mesmo os conflitos pessoais resolvidos em plena calçada (Amaral, 2005).

A população soteropolitana pobre procurava meios para prover sustento no núcleo da cidade. Desta forma, construíam seus casebres próximo aos locais em que tinham facilidade maior para trabalhar (Sanches, 1998), principalmente nas imediações das feiras e casas de famílias mais abastadas. A circulação desse contingente de pobres no centro da cidade 
preocupava as autoridades e era motivo de críticas diárias nos jornais, o que expressava o incômodo das elites. Essa preocupação resultou na criação de políticas de controle social que visavam estabelecer novos costumes (Oliveira, 2003).

As publicações diariamente registradas nos jornais denotam tal desconforto. Em matérias com grande destaque nas primeiras páginas falava-se da presença de mendigos nas ruas. $\mathrm{O}$ Diário de Notícias (5 set. 1911, p.3) afirmava que vários países europeus, principalmente a França, estavam em busca da resolução desse problema que se ampliava nas cidades e incomodava a ordem pública. A matéria argumentava sobre um artigo do escritor português João Grave, que se referia aos mendigos em Lisboa e à desordem pública na capital portuguesa. Porém, ao concluir seus comentários sobre o artigo em questão, o editor afirma que tudo que o autor escrevera sobre Lisboa aplicava-se ao Brasil.

Os depoimentos expressam o quanto as elites tinham na Europa o seu referencial de civilidade. A matéria mostra que o Brasil vivenciava problemas comuns aos que ocorriam em algumas cidades do continente europeu, mas faz uma crítica às autoridades brasileiras, que, segundo opinião expressa, não davam atenção a essa demanda que ganhava força no cotidiano das cidades.

A presença desses atores sociais nas ruas era avaliada pela imprensa como uma agressão à civilidade, pois, além de serem considerados pobres e infratores, a maioria das mulheres não se incluía no modelo de família nuclear; solteiras e muitas consideradas 'mulheres públicas'3 , sendo malvistas numa sociedade de valores cristãos e conservadores que aspirava à civilidade.

Josivaldo Pires de Oliveira (2003, p.72) afirma que "muitas dessas mulheres, que em sua vida privada eram mães de família, donas de casa, mulheres da vida, enfim, pessoas comuns das camadas populares tornaram-se personagens construídas a partir das crônicas policiais jornalísticas". As publicações veiculadas diariamente configuravam um estigma das mulheres que transitavam pelas ruas. Esse universo marcado pela complexidade das ocupações não era observado/apresentado pela imprensa, que homogeneizava todas as mulheres das ruas à imagem da 'mulher pública'.

É notável o quanto a imprensa da época hostilizava a imagem dessas mulheres, configurando a problemática do gênero no âmbito das relações cotidianas da Salvador republicana. Ao anunciarem conflitos nas ruas, os jornais publicavam notas que se referiam de forma diferente às mulheres e aos homens. Era comum matéria com manchetes como: "Mulher endiabrada!"; "Mulheres que brigam!"; "Mulheres incorrigíveis!"; "Mulheres desordeiras!". Nesses casos estavam as mulheres nas ruas, promovendo desordens ou com comportamentos julgados incivilizados. Matérias dessa natureza eram publicadas diariamente nas edições dos jornais que circulavam em Salvador nas primeiras décadas do século XX, legitimando uma mentalidade patriarcal que delimitava estereótipos para a mulher.

Matérias com as mesmas reclamações, porém referindo-se aos homens, apresentavam manchetes como: "Desordens e inquérito" (Diário de Notícias, 30 jan. 1911, p.3). O jornal não anunciava na manchete o sujeito que supostamente estava cometendo a irregularidade, posição bem diferente daquela reservada ao gênero feminino.

Através dessas matérias a imprensa construía representações simbólicas acerca dessas mulheres, consolidando uma opinião pública sobre as mesmas. Era justamente por meio 
desse veículo formador de opinião que os médicos da Faculdade de Medicina da Bahia buscavam discutir a forma como as mães baianas deveriam parir, cuidar dos seus filhos e estabelecer assim novos padrões de comportamentos.

No começo do século XX, muitas mulheres continuavam a preferir a assistência das parteiras, que transmitiam mais segurança e comodidade, visto que, até há pouco tempo, a realização de uma intervenção cirúrgica em partos, como uma cesárea, implicava grandes riscos para a mãe e para a criança. A presença de familiares da parturiente no quarto em que estava ocorrendo o parto era muito comum, pois ainda havia uma série de desconfianças e desconfortos em deixar um médico cuidar de uma mulher (Rezende, 1998).

A sociedade baiana do início do século XX tratava algumas mudanças de comportamento e ou procedimentos médicos com reservas, pois se encontrava ainda fortemente ancorada em valores dos séculos passados, principalmente no que dizia respeito ao parto e à sua medicalização (Barreto, 2000, 2007). Maria Lúcia Mott (2002, p.198) afirma que "dar à luz fora de casa era uma situação anormal, considerada apavorante e procurada apenas em casos extremos, sobretudo por pessoas classificadas como desclassificadas socialmente". Algumas barreiras tiveram que ser rompidas, tais como permitir que o corpo da mulher fosse cuidado por um homem (médico) e em outro espaço que não o doméstico - a maternidade. Muitas mulheres das classes abastadas e intermediárias possuíam reservas com relação a ter seus filhos numa maternidade.

Valores como a sacralidade do corpo feminino dificultavam a intervenção médica sobre a saúde da mulher (Adeodato Filho, 1967). Registra-se uma coexistência das duas práticas - dar à luz em casa e na maternidade - que se fez presente durante boa parte do século XX. As dificuldades que os médicos enfrentaram para se estabelecer não foi característica da Bahia ou até mesmo do Brasil. Em outros países, os médicos encontraram problemas semelhantes, a exemplo da França (Boltanski, 1984).

Nos mais variados veículos formadores de opinião na época, inclusive nos periódicos médicos e nas teses da Faculdade de Medicina, era muito comuns críticas duras às parteiras, interpretando-se suas ações como imorais e promotoras do atraso brasileiro. Entretanto, no início do século XX, essa situação começou a mudar com o advento da Maternidade Climério de Oliveira, pois a presença da parteira no interior das salas de parto e mesmo em enfermarias passou a ser constante ${ }^{4}$, diminuindo a distância entre médicos e parteiras na atividade da obstetrícia.

A afirmação científica da medicina obstétrica na Bahia passava por convencer a sociedade, especificamente as mulheres de famílias abastadas, de que a Maternidade Climério de Oliveira era um exemplo de modernidade. A medicina européia era a principal referência dos médicos brasileiros (Martins, 2004). E, nela baseada, a sociedade médica iniciou 'uma cruzada' objetivando medicalizar e higienizar os hábitos de vida da população, através das Faculdades de Medicina da Bahia e do Rio de Janeiro. A Maternidade seria um espaço em que a mulher teria apoio médico, repouso, além da assepsia, o que diminuiria o risco das infecções ${ }^{5}$ : onde o parto seria civilizado. 


\section{A imprensa e o ideal de mulher}

Ser mulher na Bahia republicana do início do século XX significava atender a um referencial cristão, baseado na imagem da mulher santa, pura e dedicada ao lar. Reforçando essa perspectiva, as mulheres pobres de Salvador tornaram-se alvo de uma série de políticas de controle que visavam 'moralizar' os costumes e civilizar aquelas que estavam fora dos padrões valorizados por uma concepção de sociedade conservadora, ainda que vestida de um discurso modernizante. As senhorinhas da elite baiana representavam o modelo a ser seguido. Elementos como casamento, práticas da caridade, práticas religiosas e bom comportamento constituíam o ideal de mulher.

Nesse contexto, a imprensa tinha um papel fundamental na definição desse perfil de mulher, bem como de um padrão de comportamento higienista. Utilizando-se de um dos seus mais importantes atributos políticos, que é formar opinião, a imprensa baiana contribuía divulgando artigos e matérias, que criticavam ou exaltavam o comportamento da mulher baiana. Alberto Heráclito Ferreira Filho (2003) afirma que a família consolidavase como instituição principal para o projeto higienista, visto que era nas relações domésticas que a sanidade física e moral era constituída. A consolidação do modelo de família nuclear e a inserção das práticas higienistas na vida da sociedade baiana era o objetivo final que movia a imprensa a apoiar tal campanha.

A situação civil das mães baianas no início do século XX preservava uma herança do período colonial, na qual grande parte das mulheres pobres vivia um cenário familiar caracterizado pela ausência dos maridos, contrariando a orientação da Igreja em prol do matrimônio (Ferreira Filho, 2003). O grande número de mães solteiras tornava cena comum no cotidiano da Bahia republicana a presença de mulheres chefiando famílias e a criação de seus filhos por parentes e vizinhos.

Ferreira Filho (2003) afirma ainda que essas mulheres não eram vítimas passivas da dominação machista. Elas agiam de acordo com impasses que lhes eram postos. A própria posição social e a forma como eram vistas pela sociedade dificultavam suas relações afetivas, pois os homens não assumiam relacionamento fixo com elas, eram as 'mulheres de rua', gerando uma grande quantidade de mães solteiras na cidade.

Em matéria publicada pelo Diário de Notícias, em 25 de janeiro de 1911, foram registradas as preocupações com a diminuição do número de casamentos na sociedade ocidental. O jornal apresentou a análise de um professor norte-americano, que afirmava que os principais motivos estavam na diminuição da capacidade financeira dos homens de sustentarem uma família. Falava também da mudança na postura da mulher que não aceitava mais ser 'escrava' do marido e, sim, companheira, pois havia alcançado independência financeira e relutava em assumir uma relação conjugal. Apontava ainda o crescente número de prazeres e divertimentos que a vida moderna oferecia e que se contrapunha "às tradicionais satisfações da vida doméstica", afastando as mulheres dos laços matrimoniais: "Desta forma o apuro da civilização diminui o encanto e o número de casamentos".

O texto jornalístico apresenta concepções diferentes acerca do casamento. Enquanto nos Estados Unidos a mulher não aceitava mais ser submissa e seguir os padrões machistas presentes no modelo de relação conjugal comum no início do século XX, na Bahia, para 
uma mulher se adequar ao referencial da boa moral, ela deveria estar na companhia e subserviência de um homem, podendo ser este um irmão, pai ou marido. No interior da maternidade, a presença do homem na condição de marido e pai da criança coadunava-se com os princípios básicos da família nuclear. ${ }^{6}$

Conformava a mentalidade da elite brasileira do início do século XX a idéia de que cabia à mulher a principal responsabilidade na educação/formação do futuro cidadão. Partia-se do princípio de que ela possuía um contato maior com a criança no processo de sua formação. Através de instituições como o Recolhimento do Santo Nome de Jesus e Internato Nossa Senhora da Misericórdia, a Santa Casa praticava a caridade cristã e disseminava valores na construção de um ideal de sociedade. A presença dessas várias instituições voltadas para a educação feminina é a evidência de que havia uma preocupação com isso, e que esta ia ao encontro dos esforços de outras instituições, como a Maternidade Climério de Oliveira e os jornais diários dedicados ao grande público.

Cumprindo o seu papel na tentativa de consolidar um perfil ideal de mulher para a sociedade baiana, o Diário de Notícias (26 set. 1922, p.1) publicou um artigo escrito pela esposa do médico Alfredo Magalhães. ${ }^{7} \mathrm{O}$ jornal referia-se a ela como a "senhora Magalhães" e trazia, no corpo do texto, referências de como deveria ser a mulher: "a mulher, destinada à soberania do amor, deverá ser a rainha do lar, o anjo de ternura e sacrifício, e sel-o-á se possuir os ordinários effeitos do amor de Deus, que vim de citar. A esposa christã sabe perdoar, suavisar as maguas, consolar, trabalhar. Mãe em gottas de amor, transmitte a seus filhos, a respeitarem seus Paes, respeitando a velhice, os mestres, e os superiores".

$\mathrm{Na}$ Bahia do início do século XX, as instituições que surgiam buscando promover políticas de apoio à mulher colocavam-na em espaços ligados ao âmbito doméstico. Não havia uma perspectiva de promoção de autonomia política e econômica. Em 24 de março de 1911, o Diário de Notícias anunciava a criação de cursos no Instituto Feminino - cozinha, arranjos de quarto, lavagem de roupa, costura, bordado - que contribuiriam para a inserção das mulheres no mercado de trabalho, preparando-as para que pudessem "ganhar a vida honestamente". Os cursos do Instituto eram para aperfeiçoar as habilidades relativas aos trabalhos no lar.

Uma edição do jornal (Diário de Notícias, 25 jan. 1911, p.1) dava destaque à cruzada que as mulheres alemãs estariam fazendo em defesa do lar. Matérias dessa natureza alimentavam muito mais a perspectiva de uma mulher doméstica do que a de uma mulher que buscasse autonomia na vida pública. A manchete não deixava dúvidas a esse respeito: "As mulheres alemãs - o seu ideal é o lar". Fazendo o seu papel de propagandista de um referencial a ser seguido pelas mulheres baianas, o jornal apresentava as alemãs (pelos menos um padrão de comportamento que se dizia ser delas) como o exemplos para as mulheres brasileiras: “As senhoras allemans não são suffragistas, e muito ao contrario. Longe de quererem tomar parte nos negocios publicos, ellas todo empenham pelo lar e esforçam-se por alli reter os esposos, os paes e filhos". Ainda na tentativa de legitimar o 'lugar' da mulher na sociedade, um outro número desse jornal (16 dez. 1916, p.2) trazia a seguinte afirmação: "A grande elevada e importante funcção da mulher nas sociedades humanas não é ser boticária, jornalista ou ser doutora, é ser mãe, é ser esposa". 
Através de publicações de artigos, poemas, noticiários sobre as conquistas feministas na Europa, a imprensa baiana discutia a educação ideal que a mulher deveria ter. Na Europa, o movimento feminista mantinha efervescente o debate sobre os direitos da mulher e a ampliação de sua atuação política e econômica na sociedade (Bock, 1993). Ao anunciar duas tendências muito discutidas entre os europeus, nas quais avaliavam o melhor destino para a educação das mulheres, o Diário de Notícias (28 dez. 1914, p.2) posicionou-se de forma um tanto ambígua. A primeira pregava a instrução da mulher para liberá-la do espaço doméstico. A segunda, totalmente contra a instrução da mulher, entendia que ela deveria servir apenas ao lar: "A mulher deve ter os bastantes conhecimentos geraes para saber, por si própria, desempenhar a nobre missão de dona de casa e mãe de família e resolver os numerosos casos que se the apresentam e que uma pessoa ignorante não pode resolver".

Simultaneamente, o jornal publicou uma matéria intitulada "Emancipação da mulher", conclamando a civilidade em nome da causa da liberdade feminina. Porém, embora mostrasse esses referenciais europeus, mantinha um discurso defendendo a manutenção da mulher no âmbito do lar. Durante o mês de fevereiro de 1917, seguiu-se uma série de matérias com o título mencionado acima.

Ao falar sobre os direitos das mães no processo de ascensão dos Estados-Providência na Europa, Gisela Bock (1993, p.436) afirma que "as lutas das mulheres pelos direitos sociais e políticos, pela cidadania e pela proteção social estiveram intimamente ligadas, e os movimentos de mulheres centraram-se, mais do que antes, nas necessidades e interesses das mulheres das classes mais baixas e na pobreza feminina".

No Brasil, as gestantes tornaram-se alvo de planejamento e políticas de apoio à mãe carente. As mulheres da elite que manifestaram preocupação com a questão da mulher não objetivavam as mesmas conquistas políticas que as feministas européias. Pretendiam uma política assistencialista, baseada na caridade que mantinha os padrões de subserviência feminina. Bock (1993) afirma que as chamadas feministas européias lutavam por subsídios que promoveriam a autonomia econômica e política das mulheres.

A igualdade que estava no cerne da filosofia iluminista européia não era voltada para as mudanças reais no cotidiano feminino. Para Elisabeth Badinter (1985, p.162), a nova ordem pregava mais a "igualdade dos homens entre si (igualdade das ordens) do que igualdade entre os seres humanos: o homem, a mulher e as crianças".

É interessante ressaltar a importância de organizações que discutiam e buscavam soluções para os problemas que permeavam o cotidiano da mulher brasileira. Destaca-se o papel de Bertha Lutz que, seguindo a influência do movimento feminista norte-americano, fundou a Federação Brasileira Para o Progresso Feminino (FBPF). Esta organização tinha como principal objetivo a defesa de mães e de crianças, além de obter garantias legislativas e práticas para o trabalho feminino.

A participação feminina nas políticas de apoio à maternidade e à infância deu-se através da filantropia. As instituições filantrópicas evidenciaram-se como o principal palco de atuação política das mulheres das camadas mais favorecidas. Ana Paula Vosne Martins (2004, p.23) chama a atenção para

a visão de gênero dos envolvidos com a questão, como também da relação entre o Estado e as mães ... os formuladores das leis e das políticas públicas tinham uma visão instrumental das 
mulheres, afinal era delas que as crianças nasciam e nascem, portanto, para ter sucesso na tarefa patriótica de salvar e preservar as crianças, era necessário olhar para as mães, protegê-las também. O problema é que ao olharem para as mães pobres os médicos, principalmente, não viam indivíduos marcados pela miséria, pelo abandono ou pelo estigma de uma gravidez fora do casamento, mas criaturas toscas, ignorantes, culpadas pela sua condição e de seus filhos.

Com o objetivo de padronizar o tipo ideal de mulher no imaginário social, a imprensa publicava matérias que definiam como deveria ser uma mulher para manter-se elegante e dentro dos preceitos da civilidade. Em uma nota de primeira página, o Diário de Notícias (21 nov. 1910) trazia um texto declarando as características que deveria ter uma mulher para ser formosa:

Quatro coisas pretas: cabelos, pestanas, sobrancelhas, pupilas.

Quatro coisas brancas: pelle, globo do olho, dentes e pernas.

Quatro coisas vermelhas: lingua, labios, gengivas, maçãs do rosto.

Quatro coisas redondas: cabeça, pescoço, antebraço, tornozello.

Quatro coisas compridas: dedos, costas, braços, pernas.

Quatro coisas largas: testa, olhos, rim, bacia.

Quatro coisas carnosas: faces, coxas, ancas, barriga das pernas.

Quatro coisas pequenas: orelhas, peitos, mãos, pés.

Textos como esse nos remetem ao padrão estético vigente na sociedade baiana do início do século XX. As mulheres atendidas na Maternidade Climério de Oliveira não se enquadravam nele. ${ }^{9}$

\section{A imprensa e a Maternidade Climério de Oliveira: uma nova agenda higienista para mães}

A maternidade da Bahia foi um projeto defendido pelos obstetras baianos desde as últimas décadas do século XIX, principalmente por Climério de Oliveira. Diante das dificuldades financeiras e da pouca participação do Estado nesse projeto, os médicos baianos movimentavam-se em busca de verbas que possibilitassem a construção da maternidade, pressionando o Senado Federal e promovendo campanhas junto a alguns segmentos da sociedade (Adeodato Filho, 1967).

Foram vários os eventos criados para arrecadar fundos a aplicar na construção da maternidade. Nas publicações diárias dos jornais era muito comum o anúncio de festivais em clubes, casas de famílias, igrejas, teatros e até mesmo em praças públicas. A maternidade levou ainda alguns anos em construção, trabalhos de retoques finais e aparelhamento, sendo inaugurada em 30 de outubro de $1910^{10}$, num terreno doado pela Santa Casa de Misericórdia, no atual bairro de Nazaré.

A sua inauguração foi noticiada com entusiasmo pelos vários jornais que circulavam na cidade, nos quais a idéia de que a modernidade chegava à saúde pública da Bahia estava presente. O Diário de Notícias de 28 de outubro de 1910 (citado em Adeodato Filho, 1967, p.37) dizia: "Causou esta inauguração a todos presentes o mais vivo entusiasmo pela organização de todas as dependências, pela correção das instalações de acordo com as exigências scientificas mais modernas, sendo o plano e direção do professor da cadeira de Clinica Obstétrica Dr. Climério de Oliveira". 
A maternidade da Bahia foi uma das primeiras criadas no Brasil com o fim específico de maternidade-escola e, inicialmente, serviria também para dar assistência às mulheres pobres e desamparadas de Salvador. Naquele momento, o êxito da obstetrícia dependia da massificação do parto medicalizado. A mulher baiana se tornava alvo de inclusão na nova ordem. Era necessário inseri-la na agenda higienista a fim de civilizar o parto.

A prática institucionalizada da ginecologia e obstetrícia foi legitimada pelos médicos, na tentativa de ampliar seu campo de atuação, estendendo o atendimento inicialmente às mulheres pobres e sem amparo social, e, concomitantemente, garantiu-se também às mulheres das famílias abastadas que o parto na maternidade era confiável.

Na França, esse processo de inserção da mulher na agenda higienista solidificou-se com um caráter mais rígido e arbitrário, impondo-se às mulheres desfavorecidas como obrigação (Grand-Sésilli, 2002). Ana Paula Vosne Martins (2000) afirma que, no Brasil, os médicos não foram tão rígidos e exigentes com as mulheres dentro da maternidade. Isso se aplica à Bahia, pois, ao analisarmos os livros de registro da Maternidade Climério de Oliveira, constatamos que são remotos os casos de mulheres expulsas por se comportarem mal ou por se insubordinarem contra os médicos. ${ }^{11}$ No entanto, não é suficiente para pensarmos em uma inserção harmoniosa da instituição maternidade na vida dessas mulheres.

Apesar de o projeto higienizador trazer nas suas premissas metodológicas a tentativa de estabelecer novos procedimentos para o parto na Bahia, é preciso compreender o quanto a ação cotidiana dessas mulheres-alvo, nos seus diversos espaços de sociabilidade, foi responsável pela forma como ele se processou. Não bastou aos médicos, munidos de um discurso modernizador e apoiados pelas camadas dominantes e pela imprensa, a apresentação de uma nova agenda para parir e convencer as mães baianas a procurarem a maternidade. Essa tarefa exigiu dos obstetras baianos habilidade também na forma de tratamento. A maternidade precisava ser um elemento atrativo para superar o estigma negativo que pesava sobre uma família quando um filho nascia numa instituição pública.

Os meios para convencer as mulheres a procurarem a maternidade foram diversos. ${ }^{12}$ Porém, a veiculação de matérias nos jornais e revistas foi o que obteve mais êxito, alcançando um número maior de pessoas. A imprensa baiana muito contribuiu para o processo de aceitação da Maternidade Climério de Oliveira na sociedade. Publicações que exaltavam a imagem dessa Maternidade, além da facilidade de acesso, eram feitas com freqüência. Poucos dias após sua inauguração, o Diário de Notícias (21 nov. 1910, p.1) ressaltou: "Para ser uma mulher internada na maternidade não é preciso formalidade alguma, bastando apresentar-se à porta. As mulheres grávidas, porém, para serem recolhidas, já devem estar no $9^{\circ}$ mêz de gravedez. As mulheres já em trabalho de parto, que forem trazidas ao estabelecimento, terão ingresso immediato, a qualquer hora do dia ou da noite".

Outra forma de estimular a procura dessa Maternidade estava nas notas de agradecimento. Com bastante freqüência o jornal as publicava; eram assinadas por pessoas bem situadas socialmente e faziam elogios aos cuidados que a Maternidade dispensara às mulheres da família. Esses anúncios possuíam um papel fundamental no processo de ruptura das resistências que as mulheres tinham à maternidade pública. $\mathrm{O}$ anúncio de que uma mulher de família abastada havia freqüentado a Maternidade Climério de Oliveira serviria como grande estímulo para as outras. Em maio de 1913, o senhor Luiz Fernandes Silva agradeceu 
publicamente o tratamento, "o carinho e delicadeza que foi dispensado à sua esposa que havia chegado em estado grave" à Maternidade e da qual saiu, posteriormente, restabelecida. Ele afirmou que a Maternidade foi "uma das mais altas conquistas no Estado da Bahia" (Diário de Notícias, 2 maio 1913, p.3).

Numa nota com o título "Tributo de gratidão" (Diário de Notícias, 23 set. 1914), Arnaldo Marques agradeceu aos médicos da Maternidade o bom atendimento dado à sua esposa, Edelvira Vieira Marques, que foi operada "devido à ruptura de uma prenhez tubária com inundação peritonal". Ao concluir o agradecimento, Arnaldo Marques afirmou que a Maternidade era "padrão de glória bahiana".

Com a manchete "Agradecimento à maternidade baiana", posta em primeira página, o Diário de Notícias (27 abr. 1914, p.1) publicou nota na qual Joaquim Manoel Sampaio manifestava gratidão à equipe de médicos da Maternidade - à qual se refere como utilíssimo e bem montado instituto - por ter cuidado da sua esposa que dali saíra restabelecida. Após mencionar vários nomes de médicos que compunham a equipe que operou a sua esposa, argumentou ainda sobre o estabelecimento e as pessoas que lá se internavam: "Posso affirmal-o, são tratados com proficiência e todo desvelo tanto as doentes pensionistas ou como as indigentes".

Notas desta natureza evidenciam a perspectiva de que a Maternidade em questão atendia também mulheres de camadas abastadas. Esses anúncios iam, aos poucos, medicalizando o parto na vida da mulher baiana, e a instituição ia sendo legitimada como um espaço de cuidado à mulher, no qual não havia desigualdade social. Entretanto, seus registros contrariam essa idéia, pois as mulheres internadas como pensionistas ficavam em alas diferentes das que eram internadas no plano conhecido como público.

A imprensa baiana contribuiu para uma verdadeira 'cruzada' promovida pela Faculdade de Medicina com objetivo de 'civilizar' os hábitos da mulher. Ao anunciar uma visita surpresa feita à Maternidade Climério de Oliveira, o Diário de Notícias (8 jul. 1915, p.1) afirmou:

\footnotetext{
Era flagrante e completo o asseio em tudo; admirável a ordem; notória a disciplina; visíveis o bem-estar e contentamento das internadas ... . Todas as enfermarias têm optimas condições de aeração e luz. Os leitos, bem separados uns dos outros, são cobertos de coletas e alvos lençóis. Junto, delicados berços com cortinas rendadas ... . A Maternidade está provida de apparelhos e instrumentos operários, os mais modernos e dos melhores fabricantes. É completo o serviço de assepsia. A bateria pharmaceutica está fornecida do necessário.
}

Anunciando facilidades de internamento, bons tratamentos, um ambiente limpo e propício ao bem-estar da parturiente, o jornal começava a convencer a mãe baiana a fazer seus partos na Maternidade. Nas revistas, através de propagandas, tentava-se atrair um segmento da população que constituía minoria no cotidiano da Maternidade Climério de Oliveira.

A revista Bahia Illustrada, em 1918, apresentava fotos de mulheres amamentando seus filhos no interior da Maternidade. Mostravam situações em que as mulheres eram bem tratadas e seguiam preceitos de uma educação voltada para o puerpério e a puericultura ${ }^{13}$, que visavam, entre outros cuidados, estimular a amamentação. Vale salientar que a amamentação era tema de discussão entre os médicos e apontada como um preceito básico no cuidado com a criança na primeira infância; uma infância saudável significaria um futuro saudável para o país. 


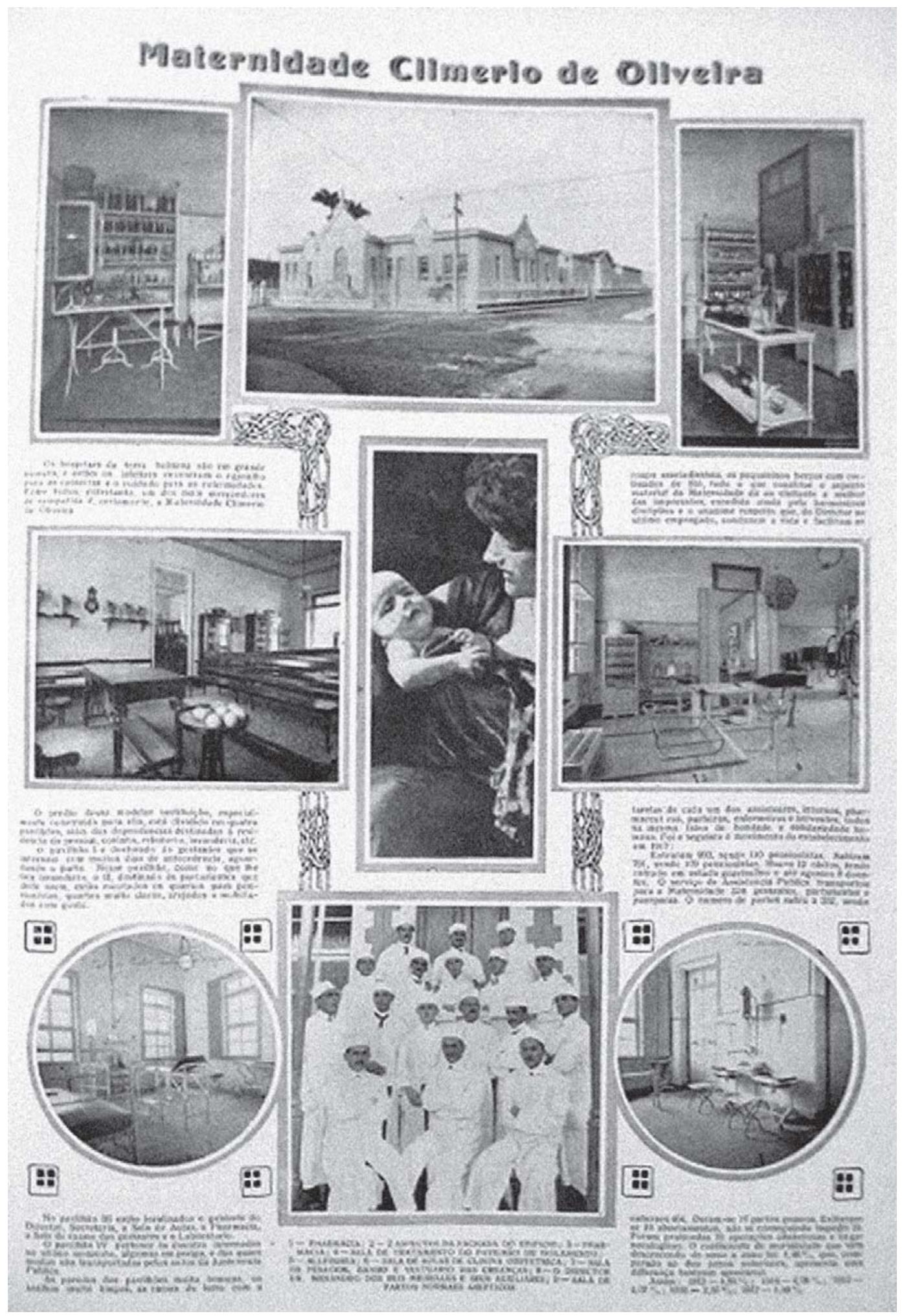

Figura 1: Detalhe da propaganda da Maternidade publicada na revista Bahia Illustrada, 1918, p.17-18 


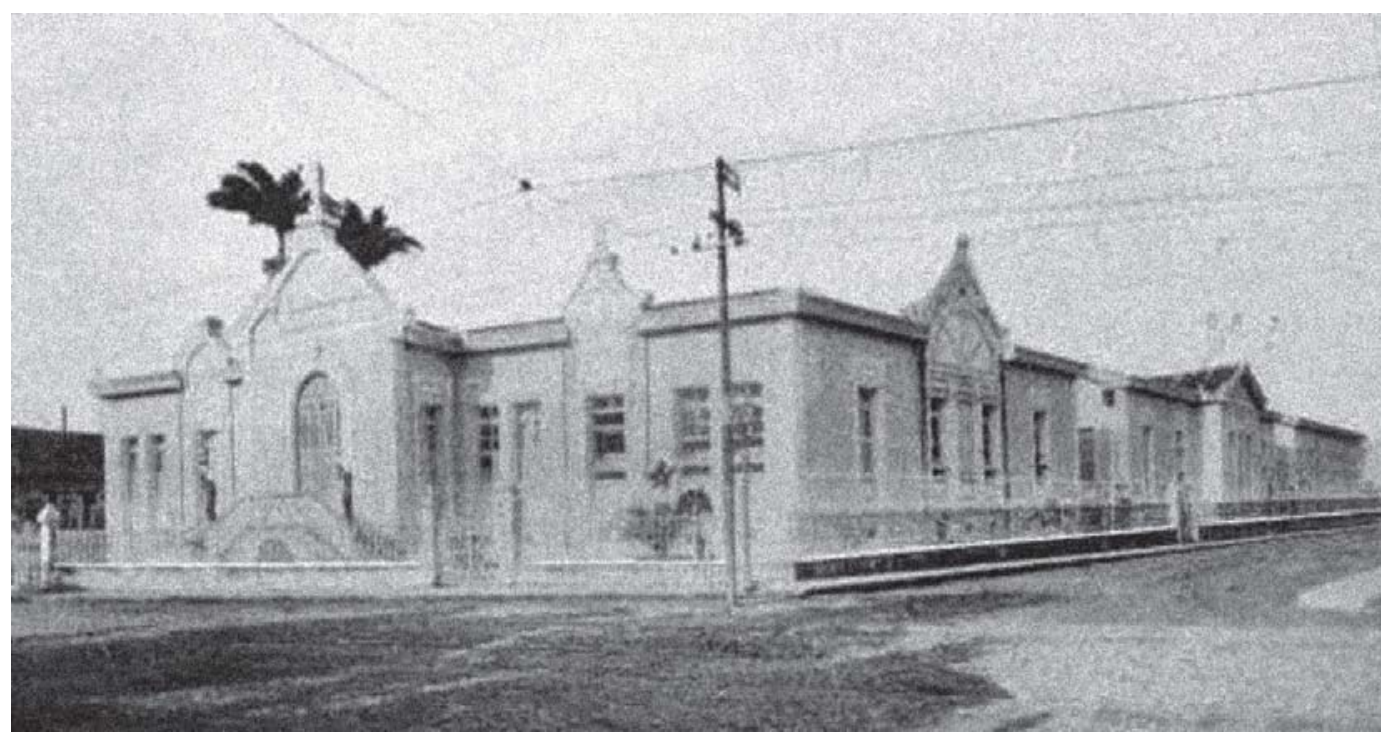

Figura 2: Detalhe da propaganda da Maternidade publicada na revista Bahia Illustrada, 1918, p.17-18

O perfil estético da mulher que está na revista representava a minoria das parturientes atendidas na Maternidade Climério de Oliveira. Os dados apresentados nos livros de registros remetem-nos a uma reflexão sobre os objetivos da revista, ao publicar tais fotos como referência, possibilitando um contraponto entre as fontes. Enquanto a imagem de uma mulher branca é publicada como o público comum da Maternidade Climério de Oliveira, os registros de internamento revelam-nos que $84,7 \%$ das mulheres ali atendidas entre 1909 e 1927 eram negras e pardas (Gráfico 1).

Uma análise comparativa entre os padrões estéticos apresentados pelos diferentes segmentos da imprensa e os dados dos livros de registros mostra que a imprensa estava presa ao compromisso de cristalizar um tipo étnico no imaginário social.

Gráfico 1: Perfil de cor das parturientes da Maternidade Climério de Oliveira (1909-1927)

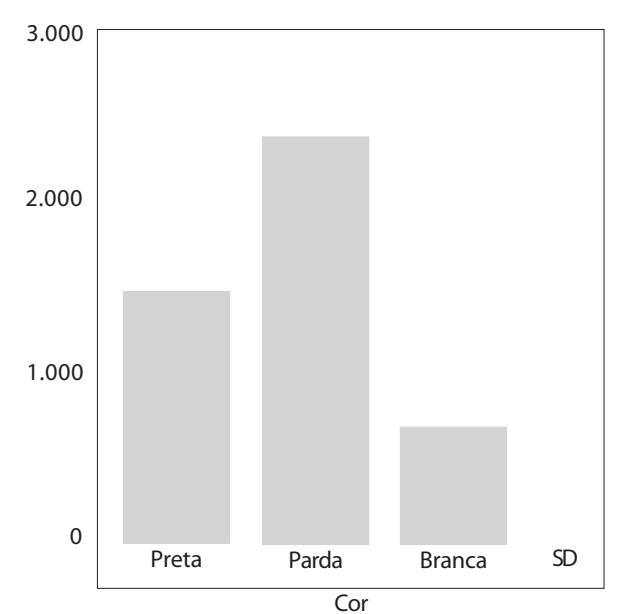

\begin{tabular}{lrr}
\hline Cor & $\mathbf{N}$ & \% \\
\hline Preta & 1.626 & 32,5 \\
Parda & 2.612 & 52,2 \\
Branca & 758 & 15,2 \\
Sem Declaração & 7 & 0,1 \\
\hline TOTAL & $\mathbf{5 . 0 0 3}$ & $\mathbf{1 0 0}$ \\
\hline
\end{tabular}

Fonte: Livro de Registro da MCO. n. 1-114, anos 1909-1927. 
Na tentativa de convencer mulheres de camadas mais abastadas, a imagem apresentada ao público era de uma estética mais presente entre as famílias providas de melhores condições econômicas, geralmente descendentes de europeus. Ao mesmo tempo em que a imprensa fazia uma campanha que visava estabelecer padrões de comportamento, legitimava também um conceito de beleza eurocêntrico. Propagandas como essas eram acompanhadas de textos que falavam das boas condições de acolhimento da Maternidade, seduzindo as mulheres para o seu interior.

Na nova agenda higienista, a instituição materno-infantil tinha atributos que visavam facilitar o processo do nascimento no interior da Maternidade. Os casos dos partos que apresentavam mais dificuldades aos olhos da parteira, para os médicos, eram resolvidos com a maior facilidade. Auxiliados pelo aparato da ciência, por meio do uso do fórceps, e até mesmo da cirurgia cesariana, os médicos passavam a representar maior segurança para as mulheres cuja gravidez era 'de risco'. O período de internamento dessas mulheres variava, em média, de 15 a 20 dias e, em alguns casos, passava de um mês (Marques, 2000). Nesse período, as mulheres passavam por ampla campanha educativa e aprendiam a cuidar de seu corpo e do corpo dos filhos dentro dos preceitos da medicina científica.

$\mathrm{O}$ tratamento dispensado pelos médicos ajudou, e muito, que as mulheres passassem a procurar a Maternidade. O médico José Adeodato Filho, em memória da Faculdade de Medicina da Bahia, escrita em 1967 e na qual fala sobre o ensino de ginecologia e obstetrícia na Bahia do início do século XX, afirmou que dar o nome de Climério de Oliveira à Maternidade significava reconhecer o mérito daquele que era bastante querido pelas mães nela atendidas. Afirmou ainda que, depois de receberem alta, elas voltavam para presenteálo com doces, frutas e alguns quitutes, reforçando o entendimento de que os médicos baianos tiveram que vencer as barreiras sociais que os distanciava dessas mulheres de modo a convencê-las de que o parto na Maternidade era mais seguro para elas e seus filhos (Adeodato Filho, 1967).

Segundo Joan Scott (1989), os elementos que constituem o gênero são ferramentas importantes para compreender o processo social. Caminhando por essa perspectiva, é possível avaliar a complexidade das relações que marcaram a obstetrícia baiana no início do século XX, bem como as distintas formas de resistência, coexistência e alianças possíveis entre as frações de diferentes camadas sociais.

O que se observa nos Livros de Registro da Maternidade Climério de Oliveira é que o número de mulheres que começou a procurar a Maternidade aumentou nos primeiros anos após sua inauguração. Atendendo inicialmente as mães pobres, os médicos conseguiram atrair as mulheres mais ricas, que começaram a ver na Maternidade um lugar seguro e confortável. A partir do terceiro ano de funcionamento, os registros trazem informações de mulheres que, por sua profissão, instrução ou condição de internamento na Maternidade, eram integrantes de camadas mais favorecidas da sociedade baiana. Aos poucos, a Maternidade deixou de atender somente mulheres pobres e marginalizadas para se abrir a mulheres das camadas médias e altas da sociedade.

A campanha desenvolvida pela imprensa baiana atingiu seu objetivo: incluir mães pobres e ricas na agenda higienista e contribuir para a medicalização do parto na cidade de Salvador. A aliança entre médicos e jornalistas cumpriu o seu papel de convencimento 
das mães. Ao analisarmos essas fontes, mudamos a maneira de encarar a medicalização do parto: retiramo-lo do cenário de imposições dos médicos e subserviência das mães para posicioná-lo no campo da sedução e persuasão através de vários meios, sobressaindo entre eles as páginas dos jornais diários.

\section{NOTAS}

${ }^{1}$ Chamamos de agenda higienista uma onda modernizante que se configurou na Europa desde o final do século XIX, quando os médicos passaram a estabelecer várias medidas de combate às doenças e disciplinarização dos indivíduos na cidade, bem como sua forma de cuidar da saúde.

${ }^{2}$ Este termo é comumente utilizado para referir-se às mulheres do movimento feminista dos anos 60 , porém chamo de feministas baianas mulheres de camadas mais abastadas que, no início do século XX, já manifestavam preocupação com a questão da mulher.

${ }^{3}$ A expressão era comumente utilizada para referir-se à prostituta.

${ }^{4}$ Temos o exemplo de Eulina Freitas Ribeiro, dona Lindu (in memorian), ex-parteira da Maternidade Climério de Oliveira, que exerceu a "arte de pegar menino" nas décadas de 1930 a 1970. Residiu no bairro do Stiep, em Salvador, até 27 de dezembro de 2004, quando faleceu. Sua entrevista foi concedida aos 89 anos, em 17 de abril de 2004.

${ }^{5}$ Livro de Registro da Maternidade Climério de Oliveira, n.3, p.20-80.

${ }^{6}$ Segundo Aparecida Sanches (1998, p.147), “além de relação segura e de base para a respeitabilidade frente à sociedade, o casamento era visto por muitas mulheres como uma maneira de deixarem de ser empregadas domésticas para tornarem-se donas de casa e, portanto, considerado como uma forma de elevação de status social".

${ }^{7}$ Importante protagonista da luta em defesa da chamada instituição materno-infantil.

${ }^{8} \mathrm{O}$ jornal não menciona seu nome, apenas a trata como a esposa do reconhecido médico.

${ }^{9}$ Livro de Registro da Maternidade Climério de Oliveira. n.1-114, anos 1909-1927.

${ }^{10}$ Apesar de inaugurada oficialmente só em 30 de outubro de 1910, a Maternidade Climério de Oliveira iniciou atendimento aproximadamente um ano antes, com parte significativa dos equipamentos já instalados. Muitas das mulheres que eram atendidas na enfermaria da Santa Casa de Misericórdia passaram a ser atendidas lá.

${ }^{11}$ Livro de Registro da Maternidade Climério de Oliveira, n.-1-25.

${ }^{12}$ A ação que o Instituto de Proteção e Assistência à Infância da Bahia desenvolvia, ao atender e dar suporte às mulheres grávidas desprovidas através da assistência domiciliar, evidencia nossa perspectiva de que a preocupação com a maternidade e a infância movimentava também instituições filantrópicas. Este era um dos meios utilizados para convencer as mulheres a realizarem seus partos na maternidade. Muitas não tinham acesso à leitura e eram atendidas em casa através da Assistência Maternal no Domicílio. Neste caso, recebiam a Caixa Maternidade, que continha peças de roupas, lençóis, camisolas de dormir, guardanapos de uso íntimo, toalhas, sabonete entre outros produtos para higiene e assepsia (Gazeta Medica da Bahia, jan. 1903, p.324).

${ }^{13}$ Cuidados estabelecidos para com a parturiente (higiene, procedimentos assépticos dentro dos preceitos médicos) antes e depois do parto, e os cuidados iniciais com a criança após o nascimento (amamentação, higienização, formas de cuidar da saúde do bebê seguindo as orientações médicas). Uma educação para a saúde higienizada.

\section{REFERÊNCIAS}

ADEODATO FILHO, José.

O ensino da clínica obstétrica na Universidade da Bahia. Salvador: Departamento Cultural da Reitoria da Universidade Federal da Bahia. 1967.
AMARAL, Marivaldo Cruz do.

Da comadre para o doutor: a Maternidade Climério de Oliveira e a nova medicina da mulher na Bahia republicana (1910-1927). Dissertação (Mestrado) - Faculdade de 
Filosofia e Ciências Humanas, Universidade Federal da Bahia, Salvador. 2005.

BADINTER, Elisabeth.

Um amor conquistado: o mito do amor materno. Trad. Waltensir Dutra. Rio de Janeiro: Nova Fronteira. 1985.

BAHIA ILLUSTRADA

Bahia Illustrada, Rio de Janeiro, v.2, n.4. 1918.

BARRETO, Maria Renilda Nery.

Nascer na Bahia do século XIX: Salvador 1832-

1839. Dissertação (Mestrado em História) -

Faculdade de Filosofia e Ciências Humanas,

Universidade Federal da Bahia, Salvador. 2000.

BASTOS, Maria Helena Camara.

Espelho de papel: a imprensa e a história da educação. In: Araújo, José Carlos de Souza; Gatti Júnior, Décio (Org.). Novos temas em história da educação brasileira: instituições escolares e educação na imprensa. Campinas: Autores Associados. p.151-174. 2002.

BOCK, Gisela.

Pobreza feminina, maternidade e direitos das mães na ascensão dos Estados-Providência (1890 - 1950) In: Duby, Georges; Perrot, Michelle. História das mulheres no Ocidente. v.5. Porto: Edições Afrontamento. p.435-477. 1993.

BOLTANSKI, Luc.

As classes sociais e o corpo. Rio de Janeiro: Biblioteca de Saúde e Sociedade. 1984.

CARVALHO, Carlos Henrique de; ARAÚJO, José Carlos Souza; GONÇALVES NETO, Wenceslau.

Discutindo a história da educação: a imprensa enquanto objeto de análise (Uberlândia-MG, 1930-1950). In: Araújo, José Carlos de Souza; Gatti Júnior, Décio (Org.). Novos temas em história da educação brasileira: instituições escolares e educação na imprensa. Campinas: Autores Associados. p.67-90. 2002.

FARIA FILHO, Luciano Mendes de. O jornal e outras fontes para história da educação mineira do século XIX: uma introdução. In: Araújo, José Carlos de Souza; Gatti Júnior, Décio (Org.). Novos temas em história da educação brasileira: instituições escolares e educação na imprensa. Campinas: Autores Associados. p.133-150. 2002.

FERREIRA, Luiz. Otávio.

Negócio, política, ciência e vice-versa: uma história institucional do jornalismo médico brasileiro entre 1827 e 1843. História, Ciências, Saúde - Manguinhos, Rio de Janeiro, v.11, supl.1, p.93-107. 2004.

FERREIRA FILHO, Alberto Heráclito. Quem pariu e bateu que balance!: mundos femininos, maternidade e pobreza em Salvador, 1890-1940. Salvador: Centro de Estudos Baianos. 2003.

FREIRE, Maria Martha de Luna.

Mulheres, mães e médicos: discurso maternalista em revistas femininas (Rio de Janeiro e São Paulo, década de 1920). Tese (Doutorado) Programa de Pós-Graduação em História das Ciências e da Saúde, Casa de Oswaldo Cruz/ Fiocruz, Rio de Janeiro. 2006.

FOUCAULT, Michel.

Microfisica do poder. 5.ed. Rio de Janeiro: Graal. 1985.

GONÇALVES NETO, Wenceslau.

Imprensa, civilização e educação: Uberabinha (MG) no início do século XX. In: Araújo, José Carlos de Souza; Gatti Júnior, Décio (Org.).

Novos temas em história da educação brasileira: instituições escolares e educação na imprensa. Campinas: Autores Associados. p.197-225. 2002.

GRAND-SÉSILLI, Catherine Le.

Quando a ordem sanitária sustenta a ordem moral: injunções feitas ao corpo de mulheres pobres. Projeto História Corpo \& Cultura, São Paulo, v.25, p.257-268. 2002.

LUZ, Adriana de Carvalho.

Mulheres e doutores: discursos sobre o corpo feminino - Salvador 1890-1930. Dissertação (Mestrado em História Social) - Faculdade de Filosofia e Ciências Humanas/Universidade Federal da Bahia, Salvador. 1996.

MARTINS, Ana Paula Vosne.

O Estado, as mães e os filhos: políticas de proteção à maternidade e à infância no Brasil na primeira metade do século XX. Humanitas, Belém, v.21, p.7-31. 2006.

MARTINS, Ana Paula Vosne. A medicina da mulher: visões do corpo feminino na constituição da obstetrícia e da ginecologia no século XIX. Campinas: s.n. 2000.

MOTT, Maria Lúcia de Barros.

Assistência ao parto: do domicílio ao hospital (1830-1960). Projeto História: Corpo \& Cultura, v.25, p.197-219. 2002.

OLIVEIRA, Josivaldo Pires de.

Pelas ruas da Bahia: criminalidade e poder no universo dos capoeiras na Salvador republicana (1912-1937). Dissertação (Mestrado em História) - Faculdade de Filosofia e Ciências Humanas, Universidade Federal da Bahia, Salvador. 2003.

REZENDE, Jorge de.

Obstetrícia. Rio de Janeiro: Guanabara Koogan. 1998. 
SANCHES, Maria Aparecida Prazeres.

Fogões, pratos e panelas: poderes, práticas e relações de trabalho doméstico: Salvador (1900 - 1950). Dissertação (Mestrado em História) Faculdade de Filosofia e Ciências Humanas, Universidade Federal da Bahia, Salvador. 1998.

SANGLARD, Gisele Porto.

Entre os salões e o laboratório: filantropia,

mecenato e práticas científicas (Rio de Janeiro,
1920-1940). Tese (Doutorado) - Programa de Pós-Graduação em História das Ciências e da Saúde, Casa de Oswaldo Cruz/Fiocruz, Rio de Janeiro. 2005.

SCOTT, Joan.

Gênero: uma categoria útil para análise histórica. Trad., Christine Rufino Dabat, M. Betânia Ávila. New York: Columbia University Press, 1989.

\section{$\rightarrow \rightarrow \rightarrow<<<$}

